\title{
INDÍCIOS DE EMPODERAMENTO DOS SUJEITOS DA EDUCAÇÃO DE JOVENS E ADULTOS EM TEXTOS AUTOBIOGRÁFICOS
}

\author{
Elma Karine Costa Cardoso* \\ Maria Aparecida Pacheco Gusmão*
}

RESUMO: Este artigo apresenta os resultados de uma pesquisa sobre o processo de empoderamento dos estudantes, na condição de sujeitos de direito, na modalidade da Educação de Jovens e Adultos (EJA), em uma escola pública localizada em um bairro periférico na cidade de Vitória da Conquista, Bahia, cujo objetivo foi averiguar a presença do Outro e indícios do processo de empoderamento nos textos de gênero autobiográfico produzidos em uma sequência didática. Para tanto, tomou-se por base os estudos de: Bakhtin (2003), Paiva (1983), Freire (1982), Arroyo (2005), Baquero (2006), Dolz, Noveraz e Schnewly (2011), entre outros. Como metodologia, a opção foi pela pesquisa-ação participativa. Os resultados comprovam que os alunos demonstram indícios de empoderamento alcançados por meio do processo educativo e se reconhecem como sujeitos de direito na esfera social.

PALAVRAS-CHAVE: Autobiografia; Educação de Jovens e Adultos; Empoderamento.

\section{Introdução}

A Educação de Jovens e Adultos (EJA) é uma modalidade formada por estudantes que apresentam traços de vida, origens, idades, vivências profissionais e escolares, ritmos de aprendizagem e estruturas de pensamento completamente variados. São pessoas com responsabilidades sociais e familiares, com valores éticos e valores morais formados a partir da experiência, do ambiente e da realidade cultural em que estão inseridos (BRASIL, 2002).

Arroyo (2005), Freire $(2005,2018)$ e outros autores também apresentam estudos que apontam que os sujeitos dessa modalidade são, em sua maioria, pessoas das classes economicamente desfavorecidas, que, em algum momento, tiveram que escolher entre o

\footnotetext{
${ }^{*}$ Mestre em Ensino pela Universidade Estadual do Sudoeste da Bahia (Uesb). Analista universitária e membro da equipe técnica do Museu Pedagógico da Uesb.

** Doutora em Educação pela Universidade Federal do Rio Grande do Norte (UFRN). Professora com grau Pleno da Universidade Estadual do Sudoeste da Bahia (Uesb), professora no PROFLETRAS (Uesb) e do Programa de Mestrado Acadêmico em Ensino (PPGEn/UESB).
} 
trabalho e a escola. Grande parte dos estudantes dessa modalidade são adultos ou já possuem idade avançada e muitos deles trabalham desde cedo. Assim, torna-se nítido que esses alunos da EJA vivenciam trajetórias de vida bastantes complexas.

Assim, ao direcionarmos o olhar para as especificidades desses indivíduos da EJA, com o reconhecimento de suas necessidades como sujeitos de direito, percebemos a necessidade de que a prática pedagógica seja conduzida no sentido de formar um sujeito consciente, político e crítico, pois, como afirma Freire (2005), a prática educativa precisa ser exercida de forma que o sujeito popular possa, por meio da reflexão, ser levado a uma discussão corajosa de sua problemática. O modelo educacional que exerce essa função de formar um ser social reflexivo é, segundo Freire, chamado de "Educação Libertadora". A base desse modelo educativo é uma pedagogia que se pauta no ser humano, mais propriamente naqueles que sofrem, para os que tiveram o direito da voz negado e a sua humanidade roubada. Para Freire (2006), essa libertação culmina num "sujeito empoderado".

O locus da pesquisa foi uma escola pública estadual de médio porte, situada na periferia da cidade de Vitória da Conquista, BA, com o objetivo de averiguar como se apresentam os indícios do processo de empoderamento nos textos de estudantes do Ensino Médio da EJA.

Por entendermos a importância de um trabalho no qual a interação do pesquisador com o objeto pesquisado é imprescindível para o sucesso do trabalho pretendido, nossa opção foi por realizar uma pesquisa-ação interventiva.

Os dados produzidos foram coletados com o uso de questionários aplicados aos alunos, observações, sessões reflexivas, filmagens e textos produzidos por meio de uma sequência didática.

\section{Metodologia}

Ao optar pelo trabalho com o público que estuda na modalidade em questão, tornase importante realizar um trabalho que parta de suas particularidades, que são suas vivências e conhecimentos de mundo. Assim, ao observar que é costume desses alunos produzirem textos orais ao contar suas histórias de vida e seu cotidiano, percebemos que tais produções 
atendem a um gênero específico, pois como afirma Marcuschi (2008, p. 154) “[...] toda manifestação verbal se dá sempre por meio de textos realizados em algum gênero”, dessa forma, a importância de trabalhar os gêneros textuais em sala de aula alia-se ao trabalho com o tipo de gênero que valorize as histórias de vida que estes alunos contam. Neste caso, o gênero autobiografia se mostrou um suporte interessante para que os alunos, por meio de uma Sequência Didática (SD), se apropriarem dos instrumentos de linguagem próprios ao gênero e pudessem compreender as diferenças entre oralidade e escrita e outros aspectos da língua.

As Sequências Didáticas (SD), segundo Dolz, Noverraz e Schneuwly (2011, p. 97), “[...] são um conjunto de atividades escolares organizadas de maneira sistemática, em torno de um gênero textual oral ou escrito". Assim, um trabalho feito a partir de atividades que utilizem a SD certamente auxilia o aluno a dominar melhor um gênero textual, ou ainda a escrever e falar dentro da norma linguistica padrão nos contextos nos quais esta variante for requerida. Outro aspecto importante, é que as atividades que envolvem gêneros textuais pressupõem atividades de leitura e produção de texto, para que os alunos se apropriem das características do gênero que produzirão, logo é de grande importância que o trabalho de produção textual seja iniciado por uma sequência de atividades que terão por objetivo uma produção final.

Ademais, esse trabalho foi realizado dentro de uma abordagem qualitativa, que se justifica pelo fato de terem caráter descritivo, relativos a pessoas, locais e conversas (BOGDAN e BIKLEN, 1994), com dados recolhidos em ambiente natural, numa sala de aula, sem uso de mensuração ou de análise de variáveis.

A pesquisa foi feita em um ambiente naturalístico, tendo como enfoque a produção e análise de dados de forma indutiva e descritiva, características de grande importância dentro da pesquisa qualitativa, pois segundo Gusmão $(2015$, p. 28) “[...] uma descrição dos problemas estudados tal como manifestados nas atividades, nos procedimentos e nas interações, ou seja, processual, requerem uma atitude de apreensão dos fenômenos de forma complexa.". O aspecto indutivo diz respeito ao comportamento que o pesquisador 
assume no decorrer do trabalho. Para Bodgan e Biklen (1994) a coleta de dados não objetiva confirmar ou informar hipóteses prévias, mas as abstrações são construídas na medida em que os dados são coletados.

A aplicação da SD foi realizada em uma turma de $1^{\circ}$ ano do ensino médio na modalidade EJA em uma escola pública estadual do município de Vitória da ConquistaBa.

\section{Resultados e Discussões: o conceito de empoderamento na pedagogia freireana}

Segundo Baquero (2006), o empowerment é um termo cujas raízes estão na Reforma Protestante iniciada por Martinho Lutero no século XVI, na Europa, num movimento de protagonismo popular na luta por justiça social que se opôs ao paternalismo. Porém, esse temo passou a ter mais notoriedade quando os movimentos sociais, contra o sistema de opressão, libertação e contracultura norte-americanos, se tornaram mais intensos e, então, passaram a utilizá-lo como sinônimo de emancipação social. Mais tarde, na década de 1990, conforme afirma Baquero (2006), obteve o apoio de movimentos sociais com vistas a afirmar o direito da cidadania sobre as diferentes esferas sociais: a prática médica, a educação em saúde, o ambiente físico, a política, a justiça e a ação comunitária.

$\mathrm{Na}$ contemporaneidade, podemos observar o uso desse termo em vários movimentos emancipatórios relacionados ao exercício de cidadania, dos negros, das mulheres, dos homossexuais, movimentos pelos direitos da pessoa deficiente, etc. Contudo, há também a noção de empoderamento como um processo social diferente da autoemancipação, proposto por Freire (2006), quando o apresenta como um termo ligado à classe social que se fortalece no coletivo e se constitui como processo e resultante de uma ação social na qual os indivíduos tomam posse de suas próprias vidas pela interação com outros indivíduos. Nessa perspectiva, o empoderamento precisa ter compromisso com a transformação da sociedade.

Para Freire (2006), esse processo está além da conquista individual ou psicológica, é uma ação coletiva que se dá na interação entre indivíduos e envolve, necessariamente, um desequilíbrio nas relações de poder na sociedade. Ele ainda afirma: 
Mesmo quando você se sente, individualmente, mais livre, se esse sentimento não é um sentimento social, se você não é capaz de usar sua liberdade recente para ajudar os outros a se libertarem através da transformação da sociedade, então você só está exercitando uma atitude individualista no sentido do empowerment ou da liberdade. (FREIRE, 2006, p. 135)

Entendido dessa forma, o empoderamento pode ser descrito como o resultado do processo de interação ou do diálogo entre os indivíduos dentro de uma sociedade.

Ainda conforme aponta Freire (2006), a educação construída por meio dessa interação dialógica é essencial para que seja desenvolvido o senso crítico do sujeito e esse modelo educacional só é possível no interior de uma pedagogia que situe o processo de aprendizagem nas condições reais de cada indivíduo. Para esse autor, a educação construída por meio do diálogo, ou educação dialógica, não é uma técnica de ensino, mas uma postura. O diálogo é um instrumento do processo de conscientização, constitui-se em “[...] um encontro dos humanos para refletirem sobre sua realidade tal como a fazem e re-fazem" (FREIRE, 2006, p. 123).

Nessa perspectiva, o diálogo está além de ser apenas um ato verbal cuja única finalidade seria a transferência de conhecimento, mas, segundo Freire (2006), é a forma de problematizar o aspecto oficial do conhecimento, questionando as relações dominantes que o produziram. O fim da educação dialógica é a educação para a transformação e a liberdade. De acordo com Freire (2018), “[...] a educação, como prática de liberdade, é um ato de conhecimento, uma aproximação crítica da realidade” (FREIRE, 2018, p. 29).

Segundo Giroux (2012), a educação, mais especificamente a alfabetização, é em si uma prática política que se mostra imbuída de significação para ambas as partes, professor e aluno. Logo, a visão freireana de educação como como prática libertadora, ainda conforme esse autor, deve considerar o aprendizado e as intenções de seu uso tanto pelo professor quanto pelo aluno, pois a noção de empoderamento do indivíduo se vale dessas ações, já que a educação, “[...] é sinal da libertação e da transformação destinadas a desativar a voz colonial e, em seguida, a desenvolver a voz coletiva do sofrimento e da afirmação silenciada sob o terror e a brutalidade de regimes despóticos” (GIROUX, 2012, p. 08). 
Assim, percebemos a importância do papel da educação como o meio pelo qual o sujeito pode vir a se tornar um ser consciente e livre e essa condição é alcançada no momento em que são estabelecidas relações com outros indivíduos, para, então, haver uma reflexão crítica e coletiva acerca de sua condição. Dessa forma, o espaço escolar na EJA precisa ser configurado de maneira que proporcione diálogos por meio dos quais esses sujeitos possam refletir sobre sua realidade e tornarem-se capazes de expressar suas necessidades, tomar suas decisões e atuar política e socialmente, com o fim de alcançar sua libertação.

Nas palavras de Dayrell (2005):

[...] ao se referir a “jovens" e "adultos", está explicitado que essa modalidade de ensino abrange os sujeitos, e não simplesmente os "alunos" ou qualquer outra categoria generalizante, e mais: sujeitos que estão situados num determinado tempo da vida, possuindo assim especificidades próprias. Ou seja, deixa claro que essa modalidade lida com dois tipos de sujeitos - jovens e adultos - que, pelo lugar que ocupam nos tempos da vida, possuem realidades específicas e assim apresentam demandas e necessidades também específicas. (DAYRRELL, 2005, p. 53-54)

Esses sujeitos apontados por Dayrell (2005) buscam uma instituição de ensino para poderem aprender coisas novas, aperfeiçoarem-se e terem oportunidade de um emprego melhor ou ainda se especializar. Há também aqueles que sonham em aprender a dominar a leitura e a escrita para ajudar os filhos nas lições de casa. além disso, de acordo com o autor supracitado, há os indivíduos marginalizados que possuem receios, medos e têm a sua autoestima abalada por não terem concluído o ensino regular no período da vida em que a maioria das pessoas o fizeram.

A escola, então, para que os sujeitos da EJA se tornem seres reflexivos e que essa reflexão alcance o nível de criticidade, deve ser pautada numa pedagogia que busque a mediação e o diálogo entre o educador e o educando para que esse último seja conduzido a se perceber como sujeito responsável por sua história. Freire (2006) assevera que o diálogo faz parte da própria natureza histórica dos seres humanos e é uma postura necessária para que os homens se desenvolvam cada vez mais como seres críticos. 
Dessa maneira, para que o educando se assuma como ser crítico e empoderado, o educador precisa assumir sua posição de mediador entre o aluno e o conhecimento, não se portar no lugar de autoridade absoluta, ou ainda, como menciona Freire (2018), “opressor”. É preciso conduzir o discente à percepção de que ele deve se portar como agente de seu conhecimento, como produtor de cultura e saber, sejam eles escolares ou da vida.

O respeito pelo educando e ao seu protagonismo, na construção do próprio aprendizado, deve ser essencial. Assim, é necessário que o corpo docente considere a criação de espaços democráticos, lugares nos quais os alunos tenham voz e compartilhem suas dúvidas, conhecimentos e sentimentos sem medos ou constrangimentos. A escola deve auxiliar os sujeitos a lerem e a compreenderem o contexto vivido, para, por meio de reflexões, construírem e transformarem suas realidades com autonomia, a fim de ampliar os saberes construídos. Essas ações possibilitam que seja constituída uma educação emancipadora, por meio do empoderamento dos educandos da EJA, ratificando o que é afirmado por Giroux (2012) ao afirmar que a educação deve ser considerada mais que uma habilidade a ser adquirida, é preciso que ela seja observada como:

[...] uma habilidade técnica a ser adquirida, mas como fundamento necessário à ação cultural para a liberdade, aspecto essencial daquilo que significa ser um agente individual e socialmente constituído. Ainda da maior importância, a alfabetização para Freire é, inerentemente, um projeto político no qual homens e mulheres afirmam seu direito e sua responsabilidade não apenas de ler, compreender e transformar suas experiências pessoais, mas também de reconstituir sua relação com a sociedade mais ampla. Neste sentido, a alfabetização é fundamental para erguer agressivamente a voz de cada um como parte de um projeto mais amplo de possibilidade e de empowerment. (GIROUX, 2012, p. 05)

Nesse sentido, reafirmamos que a construção de empoderamento dos sujeitos da EJA deve ser mediado pelo processo educacional, pois, como afirma Giroux (2012), a educação é parte do processo pelo qual o indivíduo se torna autocrítico a respeito de sua historicidade no momento em que passa a "ler" o mundo e a refletir sobre os processos sociopolíticos, para, então, se tornar agente de transformação social. 


\section{Indícios de empoderamento em textos autobiográficos de estudantes da EJA}

Optamos pelo gênero autobiografia em nosso trabalho tornando possível a ampliação do diálogo entre educador e educando e também a oportunidade de ouvir os relatos de experiências vividas pelos sujeitos das classes da EJA. Ao partir dessa ideia, a escolha do gênero em questão pode facilitar o aprendizado da escrita, pois, ao basear o trabalho nas trajetórias de vida dos alunos, o processo de ensino-aprendizagem pode se tornar mais agradável e participativo e, ainda, contribuir para a reconstrução de suas histórias de vida e fortalecer suas atitudes cidadãs.

Volponi (2015, p. 61), ao citar Ecléa Bosi, lembra que “[...] enraizar-se é um direito fundamental do ser humano e que negar esse direito traz consequências graves para a cultura e para a vida em sociedade". Com essa afirmação, a autora destaca a perspectiva de que toda história de vida merece ser contada por ser, cada uma em sua particularidade, extraordinária e rica e, portanto, merecem ser escritas e lidas.

A importância de um trabalho que valoriza as histórias de vida de alunos que fazem parte de uma modalidade educativa cheia de especificidades como a EJA não é apenas didática, mas social e individual. Para Freire (2004), dentro da prática pedagógica, é essencial que o educador, em sua relação com o educando, leve-o a " [...] assumir-se como ser social e histórico, como ser pensante, comunicante, transformador, criador, realizador de sonhos [...]" (FREIRE, 2004, p. 41).

Rodrigues e Santos (2017) argumentam que "É fundamental incentivar as potencialidades dos sujeitos que procuram a EPJAI ${ }^{1}$, pois existem outras instâncias sociais que produzem e socializam conhecimentos". Incentivar suas potencialidades e valorizar suas histórias é uma das bases do trabalho com essa modalidade.

${ }^{1}$ Educação de Pessoas Jovens, Adultas e Idosas. Os autores fazem uso da sigla com a finalidade de especificar que há um público formado, especificamente, por pessoas idosas que precisam ter sua presença registrada dentro 
As produções investigadas, portanto, fazem parte de um universo de 12 textos escritos na etapa de produção inicial (PI), e outros 12 escritos no final das atividades de intervenção, ou produção final (PF). Foi feito o uso das siglas PI e PF e nomes fictícios para identificar os autores.

Baseados na escolha de um gênero discursivo para o trabalho de produção textual, atendemos a uma orientação dos PCNs (BRASIL, 1998) e também da BNCC (BRASIL, 2017) com a observação do discurso, sua concepção sobre a educação e o significado desta para que o sujeito se torne empoderamento.

Os alunos da modalidade de EJA se mostraram interessados e bastante ativos ao encontrar um material que trabalhasse com suas especificidades, pois isso lhes possibilitou, ao mesmo tempo em que falavam de suas vivências, fossem se percebendo como sujeitos sociais de direito.

Ao analisar o questionário aplicado aos alunos, notamos que o nosso público era formado por adultos, com a faixa etária entre 18 e 44 anos, que foram alfabetizados entre os 4 e 8 anos de idade.

Sobre os motivos que os trouxeram de volta à escola, o maior número de alunos pesquisados deu respostas que nos mostraram terem a visão de que a educação é um meio para alcançarem melhoria de vida e melhores oportunidades de emprego. Algumas das respostas podem ser observadas logo abaixo:

Figura 1 - Resposta do questionário

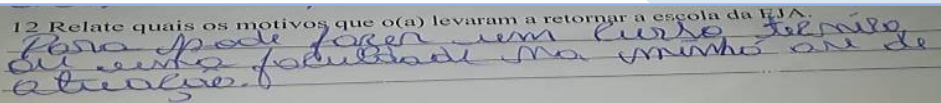

Fonte: Dados da pesquisa, 2019.

Transcrição da figura 1

12 Relate os motivos que o (a) levaram a retornar à escola na modalidade da EJA. 
Figura 2 - Resposta do questionário

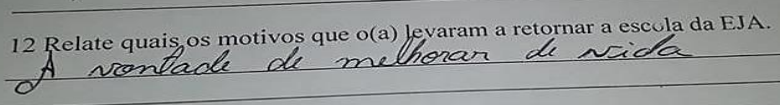

Fonte: Dados da pesquisa, 2019.

Transcrição da figura 2

12 Relate os motivos que o (a) levaram a retornar a escola da EJA. A vontade de melhorar de vida

Para a análise dos textos produzidos, uma das categorias elaboradas foi a observação de como os sujeitos percebem a importância da escola para suas vidas e de que forma a escola age como meio de libertação e empoderamento social, com base no Quadro 1, que se segue.

Quadro 1 - A educação como agente transformador

\begin{tabular}{|l|l|}
\hline \multirow{2}{*}{$\begin{array}{l}\text { A educação como } \\
\text { agente de transforma- } \\
\text { ção social }\end{array}$} & Oportunidade de crescimento profissional \\
\cline { 2 - 2 } & Melhoria de vida \\
\cline { 2 - 2 } & Empoderamento \\
\hline
\end{tabular}

Fonte: Elaborado pelas autoras, 2019.

Para muitos alunos, estar na escola representa a possibilidade de conseguirem um emprego e para os que já trabalham é a chance de poderem ter uma melhor colocação, ou ainda, segundo mencionaram, conseguirem fazer um curso técnico ou faculdade após a conclusão do ensino médio.

Temos, como exemplo dessa afirmação, o trecho retirado da PF do aluno Silas, como ilustra a Figura 3, a seguir: 


\begin{tabular}{|c|c|}
\hline 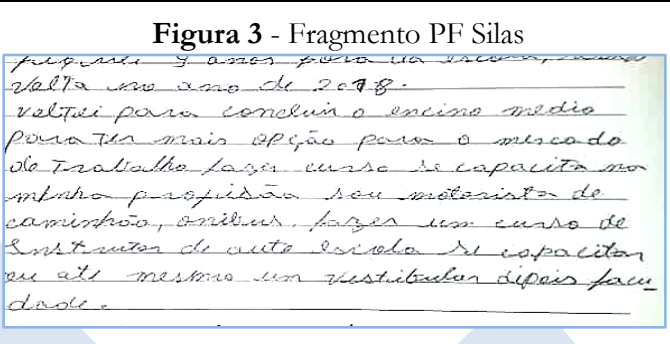 & $\begin{array}{l}\text { Transcrição da Figura 3: Frag- } \\
\text { mento PF Silas } \\
\text { [...] voltei para concluir o encino mé- } \\
\text { dio para ter mais opção para o mer- } \\
\text { cado de trabalho fazer curso se capa- } \\
\text { cita na minha profissão sou moto- } \\
\text { rista de caminhão, ônibus, fazer um } \\
\text { curso de instrutor de auto escola se } \\
\text { capacitar ou até mesmo um vestibu- } \\
\text { lar depois faculdade. }\end{array}$ \\
\hline
\end{tabular}

Fonte: Dados da pesquisa, 2019.

Observamos que, entre os vários motivos elencados pelos sujeitos para justificar seu retorno à sala de aula encontra-se a crença de que por meio dos estudos podem conseguir um futuro mais confortável, já que para esses indivíduos a conclusão do ensino médio significa a possibilidade de alcançarem um nível mais elevado em sua carreira, poderem ingressar em um curso de capacitação ou ainda cursar o nível superior. Podemos perceber essas afirmações na transcrição da PF de Silas: “[...] concluir o ensino médio para ter mais opção para o mercado de trabalho fazer curso se capacita na minha profissão [...] ou até mesmo um vestibular depois faculdade".

Observamos também as afirmações feitas por Pedro na PI (Figura 4):

\begin{tabular}{|c|c|}
\hline 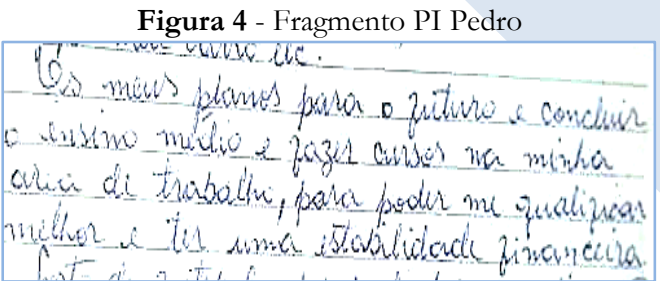 & $\begin{array}{l}\text { Transcrição da Figura 4: Frag- } \\
\text { mento PI Pedro } \\
\text { Os meus planos para o futuro e } \\
\text { concluir o ensino médio e fazer } \\
\text { cursos na minha área de trabalho, } \\
\text { para poder me qualificar melhor } \\
\text { e ter uma estabilidade financeira } \\
{[\ldots . .}\end{array}$ \\
\hline
\end{tabular}

Fonte: Dados da pesquisa, 2019.

Notamos que a mesma ideia expressa por Silas também consta no fragmento da PI de Pedro, quando ele afirma que com a conclusão do ensino médio pretende: “[...] fazer cursos na minha área de trabalho, para poder me qualificar melhor e ter uma estabilidade financeira.”. Conforme afirmação de Arroyo (2005), os jovens e adultos que trabalham durante o dia e estão na escola à noite enfrentam essa exaustiva rotina por terem consciência do que buscam e, por isso, dão valor aos seus estudos. 
Abaixo, na PF de Samuel (Figura 5), podemos observar os motivos de seu retorno à escola:

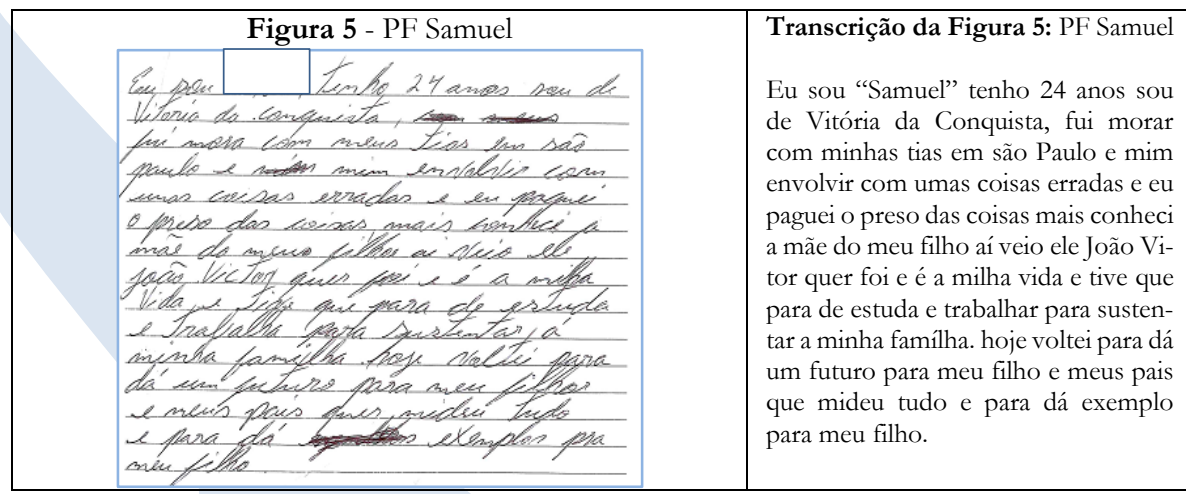

Fonte: Dados da pesquisa, 2019.

Nesse texto final, percebemos que a escola representa a possibilidade de dar um futuro melhor para seu filho, assim, para esse aluno, a escola é o meio pelo qual ele conseguirá alcançar seus objetivos.

É percebido que um dos aspectos importantes no ato de estudar, é a possibilidade de passarem isso como lição para seus descendentes, assim como a perspectiva de conseguir um melhor emprego. Essas são algumas das razões sociais que são discutidas por Prado e Reis (2012) quando estes afirmam que alguns dos fatores que levam os alunos de volta à escola são: meio para arrumar um serviço melhor e para aprenderem um pouco mais, fazer amigos, passeios, troca de experiências, etc.

Outra visão do papel da escola pode ser vista no trecho transcrito da PF do aluno José, na Figura 6, adiante. 


\begin{tabular}{|c|c|}
\hline Figura 6 - Fragmento PF José & $\begin{array}{l}\text { Transcrição da Figura 6: frag- } \\
\text { mento PF José }\end{array}$ \\
\hline 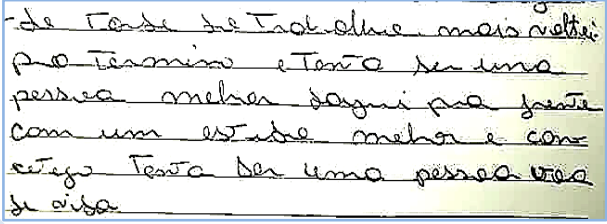 & $\begin{array}{l}{[. . .] \text { mais voltei [a estudar] pra termi- }} \\
\text { nar e tenta ser uma pessoa melhor } \\
\text { daqui pra frente com um estudo } \\
\text { melhor e com certeza tenta ser uma } \\
\text { pessoa boa de vida. }\end{array}$ \\
\hline
\end{tabular}

Fonte: Dados da pesquisa, 2019.

Para muitos sujeitos, a escola não representa apenas a possibilidade de conseguir um melhor emprego e assim poder melhorar o padrão de vida financeiramente, simboliza também a possibilidade de melhorar como pessoa. O fragmento "[...] pra terminar e tentar ser uma pessoa melhor" mostra que para esse aluno a educação também pode gerar crescimento pessoal.

A seguir, selecionamos dois trechos, o primeiro da PI da aluna Ester (Figura 7) e outro da PI da aluna Maria (Figura 8) - apresentamos esse fragmento do texto dessa aluna, mesmo ela não tendo participado da PF, pois julgamos interessante mostrar que a sua ideia sobre a escola se assemelha a de sua colega Ester:

\begin{tabular}{|c|c|}
\hline Figura 7 - Fragmento PI Ester & \\
\hline 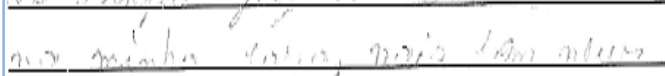 & $\begin{array}{l}\text { Transcrição da Figura 7: frag- } \\
\text { mento PI Ester }\end{array}$ \\
\hline 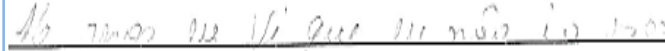 & {$[\ldots]$ mas com meus 16 anos eu vi } \\
\hline 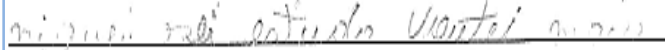 & $\begin{array}{l}\text { que eu nao ia ser niguel ser estudo } \\
\text { voutei }[\ldots . .\end{array}$ \\
\hline 3 & \\
\hline
\end{tabular}

Fonte: Dados da pesquisa, 2019.

Figura 8 - Fragmento PI Maria

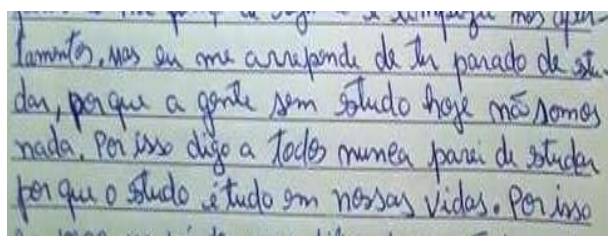

Transcrição da Figura 8: fragmento PI Maria

Mas eu me arrependi de ter parado de estudar, porque a gente sem estudo hoje não somos nada. Por isso digo a todos nunca parei de estudar porque o estudo é tudo em nossas vidas.

Fonte: Dados da pesquisa, 2019. 
Conforme afirmação de Freire (2018), a educação é o meio pelo qual o homem se torna um sujeito reflexivo e crítico que pode se libertar por meio da conscientização, consciência essa que, ainda segundo Freire (2018), “[...] abre-se para a prática da liberdade [...]", por meio da qual o homem se "hominiza" e se coloca num processo de humanização. Ao alcançar sua humanização, o homem se torna um ser consciente e livre, empoderado, capaz interagir politicamente e de lutar pelos direitos de outros indivíduos também se tornarem livres.

Contudo, é importante observar que o empoderamento do homem por meio da educação não acontece de forma isolada. Conforme postulado por Freire (2018), o homem se educa em união, de forma dialógica, quando o sujeito constrói seu senso crítico por meio de reflexões que se constituem sempre nas relações do homem com o mundo.

Assim, a função do homem que alcançou sua libertação, se tornou empoderado mediante a educação é agir a fim de levar outros a também refletirem sobre sua condição e por meio dessa reflexão alcançarem a práxis, a transformação do mundo.

Este modelo problematizador da educação, o qual deve romper com o que Freire (2018) chama de "educação bancária" cuja concepção de educação é tida como uma "caridade" praticada pelos "detentores do saber" e consideram os educandos como uma "tábula rasa", sujeitos que não participam do processo pedagógico, deve realizar-se como prática da liberdade por meio do diálogo. Por esse pressuposto, dentro desse contexto, surge a conscientização cuja intenção é o desenvolvimento crítico e a tomada de consciência e esses dois culminam na atitude crítica, que se opõe à alienação (FREIRE, 2018).

Dessa forma, no processo de ensino-aprendizagem é fundamental que a dialogicidade seja o fio condutor para uma consciência crítica, e assim a educação se mostra como um meio para que o educando desenvolva o ato de libertação em comunhão com outros sujeitos.

Apresentamos, a seguir, o fragmento do aluno Tiago, na Figura 33 e transcrito, o qual resume as ideias apontadas acerca do papel da educação para os indivíduos deste estudo. 
Figura 1 - Fragmento PF Tiago

tho oul en deike prat essu norrage

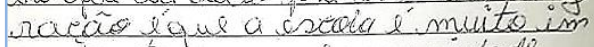
portan te nana a humanidade. trom a siscala padionos efiegar.

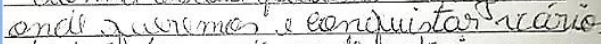
clutácules nociumes decalorir mum do morics e va tormar algiende rerdade ma risala por isso ris

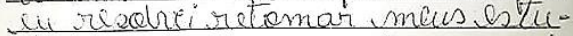
dos lssa jownara bi recomielimoanede.20 Is
Transcrição da Figura 33: fragmento PF Tiago

[...] [conselho] que eu deixo pra essa nova geração é que a escola é muito importante para a humanidade.

Com a escola podemos chegar onde queremos e conquistar vários obstáculos podemos descobrir mundos novos e se tornar alguém de verdade na vida por isso que eu resolvi retomar meus estudos essa jornada eu recomecei no ano de 2015 .

Fonte: Dados da pesquisa, 2019.

As palavras de Tiago ilustram o que Freire nos aponta sobre a tomada de consciência por meio da educação dialógica, que empodera o sujeito, ao afirmar que "[...] é preciso fazer desta conscientização o primeiro objetivo de toda a educação: antes de tudo provocar uma atitude crítica, de reflexão, que comprometa a ação” (FREIRE, 1980, p. 90). Para essa conquista, Freire $(2006,2018)$ defende o diálogo como veículo pedagógico principal da educação conscientizadora que busca a liberdade como um processo humanizador, contra a alienação e contra a opressão. Para este autor, “[...] a educação é um ato de amor, por isso, de coragem. Não pode temer o debate. A análise da realidade não pode fugir da discussão criadora, sob pena de ser uma farsa” (2018, p. 96). Assim, como base fundamental para a democracia, o diálogo tem a função de viabilizar o entendimento político e a formação humana.

\section{Considerações Finais}

Neste artigo trouxemos trechos de textos autobiográficos de estudantes da Educação de Jovens e Adultos que evidenciam indícios de empoderamento. A base teórica foi a pedagogia freireana. A análise empreendida aponta que os discentes, por meio dos textos escritos, já se apresentam num estágio no qual que têm a posse de sua própria vida. Conforme já discutido, Freire (2018) afirma que apesar de o empoderamento individual precisar ser visto com certo cuidado e, também, de não ser suficiente, ele é necessário, pois é con- 
dição essencial para o processo de transformação social. Dessa maneira, conforme as palavras desse autor, "[...] indica um processo político das classes dominadas que buscam a própria liberdade da dominação, um longo processo histórico em que a educação é a frente de luta" (FREIRE, 2018, p. 138).

Assim, percebemos que para os sujeitos participantes dessa pesquisa a escola tem a função de ser o local onde eles alcançarão sua libertação ou ainda poderão conseguir condições de progredir financeira e humanamente. E para que isso ocorra, é preciso que antes de tudo a escola seja um ambiente acolhedor, no qual os indivíduos sintam que podem realizar todas as suas aspirações, e isso só será possível no momento em que a prática pedagógica se fizer, como ressalta Freire (2018), de forma problematizadora, capaz de romper com a prática educativa que apenas transfere conteúdos de forma impositiva. Nesse sentido, é necessário que o modelo educacional a abraçar esses sujeitos respeite suas especificidades e leve-os a uma construção dialógica do seu conhecimento.

\title{
INDICATIONS OF EMPOWERMENT OF SUBJECTS OF YOUTH AND ADULT EDUCATION IN AUTOBIOGRAPHIC TEXTS
}

\begin{abstract}
This article presents the results of a research on the students' empowerment process, as subjects of law, in the Youth and Adult Education (EJA) modality, in a public school located in a peripheral neighborhood in the city of Vitória da Conquista, Bahia, whose objective was to ascertain the presence of the Other and evidence of the empowerment process in autobiographical texts produced in a didactic sequence. For that, it was based on the studies of: Bakhtin (2003), Paiva (1983), Freire (1982), Arroyo (2005), Baquero (2006), Dolz, Noveraz and Schnewly (2011), among others. As a methodology, the option was for participatory action research. The results show that students demonstrate evidence of empowerment achieved through the educational process and recognize themselves as subjects of law in the social sphere.
\end{abstract}

KEYWORDS: Autobiography; Empowerment; Youth and Adult Education

\section{REFERÊNCIAS}

ARROYO, M . Educação de jovens e adultos: um campo de direitos e de responsabilidade pública. In: SOARES, L. J. G.; GIOVANETTI, M. A.; GOMES, N.L. Diálogos na educação de jovens e adultos. Belo Horizonte: Autêntica, 2005. p. 19-50.

BAQUERO, R. V. A. Empoderamento: questões conceituais e metodológicas. Redes, Santa Cruz do Sul, v 11. n. 2, p. 77-93, maio /agosto 2006. 
BAQUERO, R. V. A. A situação das Américas: democracia, capital social e empoderamento. Revista Debates, Porto Alegre, v. 6, n. 1, p.173-187, jan.-abr. 2012.

CAMARGO JÚNIOR; S. B.; SANTOS, J. J. R.; Teorias dos direitos fundamentais e suas contribuições para o campo da educação de pessoas jovens, adultas e idosas. In:

SANTOS, J. J. R.; PEREIRA, S. M. C.; WESCHENFELDER, L. M. (Orgs.). Educação de Pessoas Jovens, Adultas e Idosas: interfaces entre direito à educação popular, currículos (s) e saberes experienciais. Passo Fundo: UFP, 2017. 21-43.

BOGDAN, R.; BIKLEN, S. K. Investigação qualitativa em educação: uma introdução à teoria e aos métodos. Porto: Porto Editora, 1994.

DAYRELL, J. T. A juventude e a educação de jovens e adultos: reflexões iniciais novos sujeitos. In: SOARES, Leôncio; GIOVANETTI, Maria Amélia; GOMES, Nilma Lino (Org.). Diálogos na educação de jovens e adultos. Belo Horizonte: Autêntica, 2005. p. 53-67.

DOLZ, J.; NOVERRAZ, M.; SCHNEUWLY, B. Gêneros orais e escritos na escola. Campinas, SP: Mercado de Letras, 2011.

FREIRE, P. Educação como prática da liberdade. Rio de Janeiro: Paz e Terra, 2005. . SHOR, I. Medo e Ousadia, o cotidiano do Professor. São Paulo: Paz e Terra, 2006. . P.; Pedagogia do Oprimido. São Paulo: Paz e Terra, 2018.

GIROUX, H.; Alfabetização e a Pedagogia do Empowerment Político. In: FREIRE, P.; MACEDO, D. (Orgs). Alfabetiz̧ação: leitura do mundo, leitura da palavra. São Paulo: Paz e Terra, 2002.

GUSMÃO, M. A. P. A (re)escrita de textos: a prática pedagógica da professora Maria. Vitória da Conquista: Edições UESB, 2015.

MARCUSCHI, L. A. Produção textual, análise de gêneros e compreensão. São Paulo: Parábola, 2008.

VOLPONI, M. de L. Gênero textual autobiografia em aulas de Lingua Portuguesa na EJA: uma perspectiva de aprendizagem na terceira idade. 161f. Dissertação (Mestrado em Letras). Universidade Estadual de Maringá, Maringá, 2015.

Recebido em: 08/04/2020 Aprovado em: 22/05/2020. 